\title{
Assessment of Heterosis for Root Yield and Attributing Traits in Ashwagandha [Withania somnifera (L.) Dunal]
}

\author{
Adithya P Balakrishnan ${ }^{11} \mathbb{O}$, N. B. Patel ${ }^{1}$ and M. P. Patel ${ }^{2}$ \\ ${ }^{1}$ Dept. of Genetics and Plant Breeding, C. P. College of Agriculture, S. D. Agricultural University, Sardarkrushinagar, Gujarat \\ (385 506), India \\ ${ }^{2}$ Pulses Research Station, S. D. Agricultural University, Sardarkrushinagar, Gujarat (385 506), India
}

Open Access

Corresponding $邓$ apb6507@gmail.com

0000-0001-7556-2444

\section{ABSTRACT}

\begin{abstract}
A study was conducted was conducted to estimate the extent of heterosis for root yield and attributing traits in ashwagandha at the Botanical Garden, Department of Genetics and Plant Breeding, C. P. C. A, S. D. Agricultural University, Sardarkrushinagar, Gujarat, India. Thirty six hybrids were generated from the diallel mating design of 9 diverse parents during October 2018 - March 2019 (rabi season). Fourty five entries were evaluated in RBD with 3 replications during October 2019-March 2020 (rabi season) for the yield and attribuiting traits. The root traits are given more emphasis because of its economic value.All the forty-five genotypes exhibited moderate to good mean performance along with an adequate amount of variability among and between the parents and hybrids. Most of the hybrids showed highly significant better parent and standard heterosis in desirable direction for the traits considered. The hybrids like SKA 10×JA 20, JA 134×AWS 1, SKA 24×SKA 26, SKA 24×AWS 1, SKA 11×AWS 1, SKA 11×SKA 26 and JA 20×AWS 1 were with a markedly significant heterotic response for fresh root yield trait. The results also suggest that the cross JA 134×AWS 1is appropriate to exploit heterosis in root length, fresh root yield and dry root yield. Further evaluation and generation advancement of these successful crosses can derive transgressive segregants and hybrids with high yield potential for commercialization.
\end{abstract}

KEYWORDS: Ashwagandha, diallel analysis, heterosis, hybrids, standard heterosis

Citation (VANCOUVER): Balakrishnan et al., Assessment of Heterosis for Root Yield and Attributing Traits in Ashwagandha [Withania somnifera (L.) Dunal]. International Journal of Bio-resource and Stress Management, 2022; 13(1), 93-98. HTTPS://DOI.ORG/10.23910/1.2022.2485.

Copyright: (c) 2022 Balakrishnan et al. This is an open access article that permits unrestricted use, distribution and reproduction in any medium after the author(s) and source are credited.

Data Availability Statement: Legal restrictions are imposed on the public sharing of raw data. However, authors have full right to transfer or share the data in raw form upon request subject to either meeting the conditions of the original consents and the original research study. Further, access of data needs to meet whether the user complies with the ethical and legal obligations as data controllers to allow for secondary use of the data outside of the original study.

Conflict of interests: The authors have declared that no conflict of interest exists.

RECEIVED on $03^{\text {rd }}$ July 2021 RECEIVED in revised form on $25^{\text {th }}$ November 2021 ACCEPTED in final form on $16^{\text {th }}$ January 2022 PUBLISHED on $31^{\text {st }}$ January 2022 


\section{INTRODUCTION}

A shwagandha [Withania somnifera (L.) Dunal] is a solanaceous medicinal plant used in diverse medicinal systems like Ayurveda, Siddha and Unani. This quality herb possesses therapeutic value against a number of alignments such as arthritis, asthma, mental diseases, inflammation, rheumatism, infections, fever, anxiety, tuberculosis, male sexual disorders and cancer (Mirjalini et al., 2009; Hahm and Singh, 2013; Gosh and Halder, 2015). Different parts of the ashwagandha plant contain a number of chemical compounds among which the alkaloids or more specifically the withanolides hold immense importance from pharmacological point of view. The withanolides present in ashwagandha plants are species specific. $W$. somnifera and $W$. ashwagandha contains withaferin $\mathrm{A}$ as major compound, in contrast coagulin $\mathrm{L}$ is present in $W$. coagulans. Beside these this plant contains amino acids including aspartic acid, proline, tyrosine, glutamic acid, cystine, tryptophan, alanine, and elevated amount of iron. Root, leaves, fruits and seeds are the commercial parts of ashwagandha that possess medicinal properties but roots are the major commercial part which contains $0.4-1.2 \%$ alkaloids, $40-65 \%$ starch, $40-65 \%$ fibres and a minor quantity of oil (Joshi et al., 2014). Apart from the medicinal properties ashwagandha root powder is directly used as an ingredient in different recipes like fruitwhey beverages, bakery items, savoury, and snack items.

Two out of twenty-six species of Withania, namely $W$. somnifera and the wild $W$. coagulans are found in India (Kaul et al., 2005). A third species namely $W$. ashwagandha is also delineated from $W$. somnifera based on norphological, chemical and molecular studies (Kaul, 1957; Mir et al., 2010). The name Ashwagandha is originated from the Sanskrit language and is a combination of "Ashwa" means horse and "gandha" means smell (Murthy et al., 2010). It is because of the smell of this plant's root is comparable to horse sweat. The plant is native to dry regions of India, Australia, East Asia, and Africa. It grows well in a dry climate and low winter temperatures because of hardiness and drought tolerance. It is grown as a late rainy season crop as the late winter rains facilitate proper root development (Joshi et al., 2014). Major cultivated areas of India include Madhya Pradesh, Rajasthan, Gujarat, Punjab and Uttar Pradesh. Ashwagandha cultivation is a better choice for lands which is not suitable for food crops (Kothari et al., 2003). The area under the Ashwagandha crop is 1461 ha according to the 2015-16 cultivation status of Anonymous (2015-16). The annual root production in India is estimated to be about 2000 tons (Kumar et al., 2010).

The breeding works for the improvement of the ashwagandha crop are limited. Even though, some varieties were released by CSIR-CIMAP, lucknow including Poshita, Rakshita and Pratap. Jawahar 20 is a high yielding variety released from Madhya Pradesh (Khare et al., 2020). WSR is another popular variety released by CSIR-Regional Research Laboratory, Jammu. Variety GAA 1 was releaded in the year 2015 for Gujarat state by AAU, Anand. The plant flowers and sets fruits during November to February. TheThe floral architecture of both cultivated and wild populations of Ashwagandha creates conditions favouring selfing (Kaul et al., 2005). Natural variability of self-pollinated populations tends to exhaust due to selection and hybridization become necessary for further genetic improvement. The increased demand for ashwagandha in the drug industry (necessitating the development of high yielding hybrids and genetic analysis of this crop. Taking these facts into account, an experiment was conducted to record the extent of heterosis for root yield and its attributing traits.

\section{MATERIAL AND METHODS}

\subsection{Experimental material}

The experimental material consisted of nine parental lines (SKA 27, SKA 11, SKA 6, SKA 24, SKA 10, SKA 26, JA 20, JA 134 and AWS 1) and the hybrids generated by half-diallel mating design. Details of parental lines are arranged in Table 1.

\begin{tabular}{|c|c|c|c|}
\hline \multicolumn{4}{|c|}{ Table 1: Details of parental lines } \\
\hline $\begin{array}{l}\text { S1. } \\
\text { No. }\end{array}$ & $\begin{array}{l}\text { Name of } \\
\text { parental line }\end{array}$ & Pedigree & Source \\
\hline 1. & SKA 27 & IPS from MPAS 7 & S. K. Nagar \\
\hline 2. & SKA 11 & IPS from MWS 101 & S. K. Nagar \\
\hline 3. & SKA 6 & IPS from MWS 322 & S. K. Nagar \\
\hline 4. & SKA 24 & IPS from MPAS 3 & S. K. Nagar \\
\hline 5. & SKA 10 & IPS from MWS 309 & S. K. Nagar \\
\hline 6. & SKA 26 & IPS from MPAS 5 & S. K. Nagar \\
\hline 7. & JA 20 & - & $\begin{array}{l}\text { Mandsaur, } \\
\text { Madhya } \\
\text { Pradesh }\end{array}$ \\
\hline 8. & JA 134 & $\begin{array}{l}\text { Pedigree selection } \\
\text { from JA } 20 \text { and wild } \\
\text { types }\end{array}$ & $\begin{array}{l}\text { Mandsaur, } \\
\text { Madhya } \\
\text { Pradesh }\end{array}$ \\
\hline 9. & $\begin{array}{l}\text { AWS } 1 \\
\text { (Check) }\end{array}$ & - & $\begin{array}{l}\text { AAU, } \\
\text { Gujarat }\end{array}$ \\
\hline
\end{tabular}

\subsection{Crossing programme}

Crosses were attempted during rabi season (October, 2018March, 2019) at the Botanical Garden, Department of Genetics and Plant Breeding, C. P. C. A, S. D. Agricultural University, Sardarkrushinagar, Gujarat (latitudes of $24^{\circ} .31^{\prime}$ $\mathrm{N}$, longitude of $72^{\circ} .32$ ' $\mathrm{E}$ and altitude of 154.52 meters above MSL). 
The study on pollen fertility and stigma receptivity in closed flowers of $W$. somnifera (L.) shows the flower is kind of chasmogamous (Lattoo et al., 2007) and the time duration between 7.00 to 11.00 hours are most suitable for $95-98 \%$ success in hybridization. Mature flower buds of female parents about to open next day morning were selected for hand emasculation. It was carried out between 3.00 to 5.00 p.m by removing the calyx and anthers by using forceps without damaging pistils. The emasculated buds were bagged to avoid open pollination. Pollination was done next day morning between 8.00 to 11.00 am by rubbing the dehisced flower on the stigma of the emasculated flower. Pollinated flowers were bagged immediately with proper labelling. Tagging was done after the berry set and mature berries of crosses were collected separately. Seeds were stored in proper conditions after drying and threshing.

\subsection{Evaluation and recording of observations}

The 36 crosses generated along with their 9 parental lines were evaluated in Randomized Block Design with three replications during rabi 2019-2020 at Agronomy Instructional Farm, S. D. Agricultural University, Sardarkrushinagar. Each replication contained one row of each 45 entries. A row length of $4 \mathrm{~m}$ and a spacing of $30 \times 10 \mathrm{~cm}$ was maintained. Observations were recorded for ten yield and attributing traits such as days to flowering, plant height $(\mathrm{cm})$, number of primary branches, number of secondary branches, number of berries plant ${ }^{-1}$, number of seeds berry ${ }^{-1}$, root length $(\mathrm{cm})$, root girth $(\mathrm{cm})$, fresh root yield $(\mathrm{g})$ and dry root yield $(\mathrm{g})$.

\subsection{Statistical analysis}

The replication wise mean values of all these treatments were statistically analysed as per procedures suggested by Panse and Sukathme (1985). The magnitude of heterosis over better parent (Heterobeltiosis) and standard check (Standard Heterosis) were estimated as per Fonseca and Patterson (1968) and Meredith and Bridge (1972) respectively. The variety AWS-1 was considered as a check for the estimation of standard heterosis.

\section{RESULTS AND DISCUSSION}

$\mathrm{I}$ dentification of crosses with significant heterotic responses for root yield and attributing traits has immense importance in the genetic improvement of ashwagandha. This experiment targeted studying the extent of heterobeltiosis and standard or economic heterosis which is relevant to practical plant breeding.

The analysis of variance of the present investigation showed significance among the mean sum of squares due to genotypes for all traits under study (Table 2). Kumar et al. (2007), Mir et al. (2014), Srivastava et al. (2018) and Dhaka et al. (2021) reported the presence of a considerable amount of variation in various traits of ashwagandha. The mean sum of squares due to parent vs hybrids of the present study was highly significant for all traits except days to flowering and dry root yield $(\mathrm{g})$ implied the marked difference in the performances of cross combinations among them and compared to the parental lines. This available variation in the population is suitable to perform selection and to create

\begin{tabular}{|c|c|c|c|c|c|c|c|c|c|c|c|}
\hline $\begin{array}{l}\text { Sources of } \\
\text { variation }\end{array}$ & $\begin{array}{l}\text { d. } \\
\text { f. }\end{array}$ & $\begin{array}{l}\text { Days to } \\
\text { flowering }\end{array}$ & $\begin{array}{l}\text { Plant } \\
\text { height } \\
(\mathrm{cm})\end{array}$ & $\begin{array}{l}\text { No. of } \\
\text { primary } \\
\text { branches }\end{array}$ & $\begin{array}{c}\text { No. of } \\
\text { secondary } \\
\text { branches }\end{array}$ & $\begin{array}{l}\text { No. of } \\
\text { berries } \\
\text { plant }^{-1}\end{array}$ & $\begin{array}{l}\text { No. of } \\
\text { seeds } \\
\text { berry }^{-1}\end{array}$ & $\begin{array}{l}\text { Root } \\
\text { length } \\
(\mathrm{cm})\end{array}$ & $\begin{array}{l}\text { Root } \\
\text { girth } \\
(\mathrm{cm})\end{array}$ & $\begin{array}{l}\text { Fresh } \\
\text { root } \\
\text { yield } \\
(\mathrm{g}) \\
\end{array}$ & $\begin{array}{c}\text { Dry } \\
\text { root } \\
\text { yield } \\
(\mathrm{g}) \\
\end{array}$ \\
\hline Replications & 2 & 36.07 & $16.07^{*}$ & 0.04 & $2.37^{*}$ & 110.56 & 20.16 & $32.85^{*}$ & 0.59 & 1.89 & 0.21 \\
\hline Genotypes & 44 & $174.30^{\circ "}$ & $249.15^{* * t}$ & $3.69^{* *}$ & $7.11^{* *}$ & $27008.35^{* *}$ & $108.35^{* *}$ & $100.95^{* *}$ & $3.70^{* *}$ & $41.00^{* * *}$ & $2.02^{* *}$ \\
\hline Parents & 8 & $107.04^{\prime \prime \prime}$ & $154.26^{* *}$ & $1.06^{* *}$ & $6.39^{* *}$ & $4847.18^{* * *}$ & $111.33^{* *}$ & $111.86^{* *}$ & $2.54^{* *}$ & $48.69^{* * *}$ & $3.33^{* *}$ \\
\hline Hybrids & 35 & $194.59^{* * *}$ & $228.10^{* *}$ & $4.00^{* *}$ & $6.43^{* *}$ & $27733.66^{* *}$ & $92.11^{*}$ & $99.31^{* *}$ & $3.84^{* * *}$ & $39.73^{* *}$ & $1.77^{* * *}$ \\
\hline $\begin{array}{l}\text { Parent vs } \\
\text { hybrids }\end{array}$ & 1 & 2.14 & $1744.78^{* * *}$ & $14.07^{\text {w* }}$ & $36.84^{* * *}$ & $178911.83^{* * *}$ & $625.87^{* \prime \prime}$ & $71.25^{* *}$ & $8.10^{* *}$ & $24.01^{* *}$ & 0.12 \\
\hline Error & 88 & 13.82 & 4.93 & 0.18 & 0.30 & 125.23 & $12.65^{* *}$ & 4.55 & 0.30 & 1.99 & 0.14 \\
\hline
\end{tabular}

${ }^{*} p \leq 0.05,{ }^{* *} p \leq 0.01$

heterotic combinations using diverse parents. Relatable results showing the existence of variance in parents and heterotic combinations in ashwagandha for the one or more traits of the present study are evident from Dhuri (2016).

High mean performance is always a consideration in the selection of parental lines and the creation of heterotic groups. All the nine parents and 36 hybrids displayed moderate to good performance for traits under consideration. Regarding the root traits, the parents SKA 27, SKA 6 and SKA 10 were identified to be with the best performance. The majority of the hybrids exhibited superior mean performance compared to parents (mean performance 
of the entries is attached as supplementary information).

The majority of the crosses showed greater magnitudes of heterosis in the desired direction over better parent and the check (AWS 1) for root yield and its attributing traits. The details including a range of heterosis estimates and the number of crosses with significance in a positive and negative direction are arranged in Table 3 . The estimates of better parent and standard heterosis over the check AWS 1 for all the 36 crosses generated are given in the supplementary information.
The hybrids with negative significant heterosis are agronomically desirable in ashwagandha for days to flowering and plant height. Out of ten negatively significant hybrids, SKA $11 \times$ SKA 26 (-14.73\%), SKA 24×AWS 1 $(-14.54 \%)$, SKA $11 \times$ JA 20 (-13.69\%), JA 20×AWS 1 $(-10.79 \%)$ and SKA $10 \times$ JA $134(-9.28 \%)$ showed highly significant negative heterobeltiosis. The hybrids showed highly negative significance over the check AWS 1 includes SKA 10×SKA 26 (-17.46\%), SKA 26×JA $134(-17.05 \%)$, SKA $27 \times$ SKA $6(-15.38 \%)$ and SKA 11×JA $20(-13.30 \%)$.

Table 3: A summary of heterosis analysis for traits in Ashwagandha

\begin{tabular}{|c|c|c|c|c|c|c|}
\hline \multirow[t]{2}{*}{ Traits } & \multicolumn{3}{|c|}{ Better parent heterosis (\%) } & \multicolumn{3}{|c|}{ Standard heterosis (\%) } \\
\hline & Range & $\begin{array}{l}\text { No. of positive } \\
\text { significant } \\
\text { crosses }\end{array}$ & $\begin{array}{c}\text { No. of negative } \\
\text { significant } \\
\text { crosses }\end{array}$ & Range & $\begin{array}{l}\text { No. of positive } \\
\text { significant } \\
\text { crosses }\end{array}$ & $\begin{array}{c}\text { No. of negative } \\
\text { significant } \\
\text { crosses }\end{array}$ \\
\hline DF & -14.73 to 28.37 & 20 & 10 & -17.45 to 14.21 & 17 & 14 \\
\hline $\mathrm{PH}$ & -31.58 to 88.21 & 33 & 1 & -48.60 to 15.41 & 6 & 22 \\
\hline $\mathrm{PB}$ & -42.11 to 143.16 & 4 & - & -44.27 to 114.56 & 2 & - \\
\hline SB & -37.87 to 84.08 & 5 & 1 & -42.45 to 77.33 & 6 & - \\
\hline $\mathrm{BPP}$ & 44.70 to 253.90 & 27 & 8 & -64.68 to 127.89 & 17 & 19 \\
\hline SPB & -26.90 to 36.42 & 17 & 8 & -11.96 to 52.29 & 29 & 3 \\
\hline RL & -52.61 to 99.21 & 12 & 18 & -18.51 to 92.70 & 20 & 3 \\
\hline RG & -89.77 to 73.28 & 2 & 2 & -25.99 to 73.29 & 7 & - \\
\hline FRY & -78.56 to 146.50 & 9 & 13 & -28.37 to 156.61 & 21 & - \\
\hline DRY & -86.15 to 120.66 & 1 & 3 & 3.52 to 135.24 & 3 & - \\
\hline
\end{tabular}

DF: Days to flowering; PH: Plant height; PB: Number of primary branches; SB: Number of secondary branches; RL: Root length; RG: Root girth; BPP: Number of berries plant ${ }^{-1}$, SPP: Number of seeds ${ }^{-1}$; DRY: Dry root yield

For the trait plant height, only one cross exhibited negative significance over the better parent namely SKA 24×JA 134 $(-31.58 \%)$. Standard heterosis over the check AWS 1 found to be manifested in 22 crosses which includes SKA $24 \times \mathrm{JA}$ $134(-48.61 \%)$, SKA $10 \times$ SKA $26(-38.55 \%)$, SKA $6 \times$ SKA $24(-34.57 \%)$, SKA $11 \times$ SKA $6(-33.55 \%)$ etc. These results are in agreement with the findings of Arpan et al. (2014) and Sharma et al. (2016).

As the number of primary branches increases the number of berries as well as the seed yield increases. The top crosses that showed high positive significance for heterobeltiosis were SKA 24×SKA 26 (143.16 \%), SKA 10×JA 20 (105.64\%) and SKA $26 \times$ AWS 1 (14.12\%). Highly significant positive heterotic crosses over the standard check include SKA 10×JA 20 (114.56\%) and SKA 26×AWS 1 (92.12\%). The number of secondary branches was found to be correlated with the root length, diameter and fresh weight as per the findings of Arpan et al. (2014). Hence the significant heterosis for the number of secondary branches can take into account for the exploitation of hybrid vigour in the root traits as well. Four of the fourteen significant hybrids showed the heterobeltiosis in a positive direction in the case of the number of secondary branches. Crosses like SKA $2 \times$ AWS 1 (77.33\%) and SKA 27×SKA 24 (67.25\%) were with high magnitude and positive significance in the contest of economic heterosis.

For the number of berries plant ${ }^{-1}$ twenty-seven crosses were found to be significant over the better parent. The crosses SKA 27×SKA 26 (253.90\%), SKA 27×SKA 11 (242.27\%) and SKA $24 \times$ SKA 26 (214.76\%) showed higher magnitudes of heterobeltiosis. Seventeen hybrids were positively significant over the check AWS 1 . The cross SKA 27×SKA 24 (127.89\%) exhibited the highest positive significance for standard heterosis followed by SKA $27 \times$ SKA 11 (114.98\%), SKA 10×JA 134 (99.29\%) and SKA 11×SKA 26 (84.11\%). Twenty-five crosses out of the thirty-six crosses showed significance over the better parent for the trait number of seeds berry ${ }^{-1}$. Among that, twenty-three crosses were 
highly significant in a positive direction. A broad range of standard heterosis was observed for this trait and the crosses like SKA 27×JA 134 (52.29\%), SKA 27×SKA 24 (52.05\%), SKA 6×SKA 24 (49.18\%), SKA 10×JA 134 (47.55\%) and SKA $6 \times$ SKA 26 (45.62\%) manifested significant heterosis in a positive direction.

Root traits are crucial to the ashwagandha crop. The results for root length traits indicated that 30 crosses manifested significant heterosis over their respective better parents which includes SKA 27×SKA 11 (99.21\%), SKA 24×AWS 1 (92.69\%), SKA $27 \times$ AWS 1 (62.32\%), SKA 27×SKA 24 (57.27\%), SKA $11 \times$ JA 20 (49.36\%) and SKA 6×AWS 1 (28.31\%). Twenty hybrids showed highly significant positive heterosis over the check. The crosses like SKA $24 \times$ AWS 1 (92.70\%), SKA $27 \times$ SKA 11 (66.69\%), SKA $11 \times$ SKA 6 (66.26\%), SKA $27 \times$ AWS 1 (62.32\%), SKA $27 \times$ SKA 24 (56.15\%) and SKA $11 \times$ SKA 26 (54.11\%) showed highly significant standard heterosis. The estimates for root girth implied that only two crosses viz., SKA 11×JA 20 (73.28\%) followed by SKA 24×AWS 1 (56.86\%) were with significant heterobeltiosis in a positive direction. Top hybrids with the highest positive standard heterosis was SKA $11 \times \mathrm{JA}$ 20 (79.29\%) followed by SKA 6×SKA 26 (67.9\%), SKA 27×AWS 1 (65.94\%) and SKA 10×JA 20 (61.28\%).

A wide range of heterosis was exhibited by the hybrids generated for the most important traits like fresh root yield and dry root yield. Eight crosses displayed positive heterosis for fresh root yield over the better parent of which JA $134 \times$ AWS $1\left(146.50^{* *}\right)$ followed by SKA $24 \times$ SKA 26 $\left(97.75^{* *}\right)$ and SKA $24 \times$ AWS $1\left(89.95^{* *}\right)$ exhibited the highest magnitude. Significant positive heterosis for fresh root yield was also observed for 15 crosses. Among that, the top three crosses were SKA 10×JA $20\left(156.62^{* *}\right)$, SKA 6×SKA $26\left(153.19^{* *}\right)$ and SKA $24 \times$ SKA $26\left(90.46^{* * *}\right)$. The perusal estimates of heterobeltiosis for dry root yield indicated that only one cross viz., JA 134×AWS $1\left(120.66^{* *}\right)$ was highly significant in a positive direction over the better parent. The crosses JA $134 \times$ AWS $1\left(135.25^{* *}\right)$, SKA $27 \times$ SKA 10 (125.36*) and SKA 10×SKA 26 (101.33*) displayed greater magnitudes for standard heterosis.

The results derived from this study points towards the possibility of exploitation of heterosis in the ashwagandha germplasm for the improvement of root yield related traits which is in agreement with the finding of Patidar et al. (1990), Arpan et al. (2014) and Dhuri (2016). Accordign to previous reports the heterotic combinations for root yield is expected to show high total alkaloid content due to significant correlation (Kumar et al., 2011).

Hybrid vigour of the root traits is of great value since root is the major economic part of ashwagandha. Many of the significant heterotic crosses for fresh root yield revealed in this study exhibited considerable extend of heterosis in desirable direction for other attributing traits as well. The cross combinations given in Table 4 are appropriate to utilize according to the traits in which heterosis is desired in ashwagandha.

\begin{tabular}{|c|c|c|c|c|}
\hline $\begin{array}{l}\text { S1. } \\
\text { No. }\end{array}$ & Crosses & $\begin{array}{c}\text { Better } \\
\text { parent } \\
\text { heterosis } \\
(\%)\end{array}$ & $\begin{array}{c}\text { Standard } \\
\text { heterosis } \\
(\%)\end{array}$ & $\begin{array}{l}\text { Other } \\
\text { traits with } \\
\text { heterosis in } \\
\text { the desired } \\
\text { direction }\end{array}$ \\
\hline 1. & $\begin{array}{l}\text { SKA } 10 \times \mathrm{JA} \\
20\end{array}$ & $156.62^{* *}$ & $52.80^{* *}$ & $\begin{array}{l}\text { PH, PB, } \\
\text { BPP, SPB, } \\
\text { RL, RG }\end{array}$ \\
\hline 2. & $\begin{array}{l}\text { JA } 134 \times \text { AWS } \\
1\end{array}$ & $150.90^{* *}$ & $146.50^{* *}$ & $\begin{array}{l}\text { PH, SPB, } \\
\text { RL, DRY }\end{array}$ \\
\hline 3. & $\begin{array}{l}\text { SKA } \\
24 \times \text { SKA } 26\end{array}$ & $90.46^{* *}$ & $97.75^{* *}$ & BPP, SPB \\
\hline 4. & $\begin{array}{l}\text { SKA } \\
24 \times \text { AWS } 1\end{array}$ & $89.95^{*}$ & $89.95^{* * *}$ & $\begin{array}{l}\text { DF, BPP, } \\
\text { SPB, RL, } \\
\text { RG }\end{array}$ \\
\hline 5. & $\begin{array}{l}\text { SKA } \\
11 \times \text { AWS } 1\end{array}$ & $84.48^{* * *}$ & $53.28^{* * *}$ & $\begin{array}{l}\text { DF, PH, } \\
\text { SB, BPP, } \\
\text { RL, RG }\end{array}$ \\
\hline 6. & $\begin{array}{l}\text { SKA } \\
11 \times \text { SKA } 26\end{array}$ & $9381.9495^{* *}$ & $88.90^{* *}$ & $\begin{array}{l}\text { SB, BPP, } \\
\text { SPB, RL }\end{array}$ \\
\hline 7. & $\begin{array}{l}\text { JA } 20 \times A W S \\
1\end{array}$ & $54.46^{*}$ & $28.33^{*}$ & $\begin{array}{l}\text { DF, SPB, } \\
\text { RL }\end{array}$ \\
\hline
\end{tabular}

DF: Days to flowering; PH: Plant height; PB: Number of primary branches; SB: Number of secondary branches; RL: Root length; RG: Root girth; BPP: Number of berries plant $^{-1}$, SPP: Number of seeds ${ }^{-1}$; DRY: Dry root yield

\section{CONCLUSION}

$\mathrm{T}$ his study shows the possibility of heterosis breeding in ashwagandha. The crosses SKA 10×JA 20, JA 134×AWS 1, SKA 24×SKA 26, SKA 24×AWS 1, SKA $11 \times$ AWS 1 , SKA $11 \times$ SKA 26 and JA 20×AWS 1 are useful to exploit heterosis for fresh root yield. Among these JA 134×AWS 1 could be a better choice for hybrid development due to the significant heterotic response in root length, fresh root yield and dry root yield.

\section{FURTHER RESEARCH}

$\mathrm{T}$ hese hybrids can be advanced over generations to derive transgressive segregants and information about genetic components of variance. Further field evaluations and molecular analyses are suggested for the release of potential hybrids in ashwagandha. 


\section{REFERENCES}

Anonymous, 2015-16. NMPB cultivation status. Available at http://www.nmpb.nic.in. Accessed on $20^{\text {th }}$ July 2019.

Arpan, Ankesh, Shanker, K., Gupta, A.K., Jhang, T., 2014. RNA-seq analysis of two elite lines of Withania somnifera to evaluate the potential of heterosis. Indian Journal of Genetics and Plant Breeding 74(4), 612-619.

Dhaka, B., Dadheech, A., Padiwal, N.K., Choudhary, R.R., 2021. Correlation studies in ashwagandha [Withania somnifera (L.) Dunal]. Current Journal of Applied Science and Technology 40(20), 58-64.

Dhuri, H., 2016. Study of combining ability and heterosis for root quality and yield in ashwagandha $[W$. somnifera (L.) Dunal]. M. Sc. (Ag.) Thesis. Indira Gandhi Krishi Vishwavidyalaya, Raipur (C.G).

Fonseca, S., Patterson, F.L., 1968. Hybrid vigour in seven parent diallel crosses in common wheat [Triticum aestivum (L.)]. Crop Science 8, 85-89.

Gosh, B., Halder, T., 2015. Phytochemical and Pharmacological Activity of Withania somnifera (L.) Dunal. International Journal of Economic Plants 2(4), 192-196.

Hahm, E.R., Singh, S.V., 2013. Autophagy fails to alter withaniferin A-mediated lethality in human breast cancer cells. Current CAnce Drug Targets 13, 640-650.

Joshi, N.R., Patel, M.A., Prajapati, K.N., Patel, A.D., 2014. Genetic variability, correlation, path analysis in ashwagandha $[W$. somnifera L. (Dunal)]. Electronic Journal of Plant Breeding 5(4), 875-880.

Kaul, K.N., 1957. The origin, distribution and cultivation of Ashwagandha the so called Withania somnifera of Indian literature. In:Symposium on the Utilization of Indian Medicinal Plants, CSIR, New Delhi, 7-8.

Kaul, M.K., Kumar, A., Sharma, A., 2005. Reproductive biology of Withania somnifra (L.) Dunal. Current Science 88(9), 1375-1377.

Khare, C.P., Naharwar, A.V., 2020. Ashwagandha (Withania somnifera (L.) Dunal): A scientific review with respect to Ayurvedic perspectives. Annals of Phytomedicine 9(2), 134-141.

Kothari, S.K., Singh C.P., Kumar, Y.V., Singh, K., 2003. Morphology, yield and quality of ashwagandha (Withania somnifera L. Dunal) roots and its cultivation economics as influenced by tillage depth and plant population density. Journal of Horticultural Science and Biotechnology 78(3), 422-425.

Kumar, A., Kaul, M.K., Bhan, M.K., Khanna, P.K., Suri, K.A., 2007. Morphological and chemical variation in 25 collections of Indian medicinal plant, Withania somnifera (L.) Dunal (Solanaceae). Genetic Resources and Crop Evolution 54, 655-660.
Kumar, A., Mir, B.A., Sehgal, D., Dar, T.H., Koul, S., Kaul, M.K., Raina, Qazi, G.N., 2010. Utility of a multidisciplinary approach for genome diagnostics of cultivated and wild germplasm resources of medicinal Withania somnifera, and the status of new species, $W$. ashwagandha, in the cultivated taxon. Plant Systematics and Evolution 291, 141-151.

Kumar, R.K., Anjaneya Reddy, L.P., Subbaiah, J.C., Kumar, A.N., Nagendra Prasad, H.N., Bhukya, B., 2011. Genetic association among root morphology, root quality and root yield in ashwagandha (Withania somnifera). Genetika 43(3), 617-624.

Lattoo, S.K., Dhar, R.S., Khan, S., Bamotra, S., Dhar, A.K., 2007. Temporal sexual maturation and incremental staminal movement encourages mixed mating in Withania somnifera - An insurance for reproductive success. Current Science 92(10), 1390-1399.

Meredith, W.R., Bridge, R.R., 1972. Heterosis and gene action in cotton (Gossypium hirsutum). Crop Science. 12, 304-310.

Mir, B.A., Khazir, J., Hakeem, K.R., Kumar, A., Koul, S., 2014. Withanolides array of Withania ashwagandha sp. novo populations from India. Industrial Crops and Products 59, 9-13.

Mir, B.A., Koul, S., Kumar, A., Kaul, M.K., Soodan, A.S., Raina, S.N., 2010. Intraspecific variation in the Internal Transcribed Spacer (ITS) regions of rDNA in Withania somnifera (L.) Dunal. Indian Journal of Biotechnology 9, 325-328.

Mirjalili, M.H., Moyano, E., Bonfill, M., Cusido, R.M., Palazon, J., 2009. Steroidal lactones from Withania somnifera, an ancient plant for novel medicine. Molecules 14, 2373-2393.

Panse, V.G., Sukathme, P.V., 1985. Statistical methods for agricultural workers. ICAR Publication, New Delhi.

Patidar, H., Kandalkar, V.S., Nigam, K.B., 1990. Hybrid vigour in Ashwagandha. Current Research-University of Agricultural Sciences (Bangalore) 9(11), 191-193.

Sharma, T.K., Pant, S.C., Kumar, K., Kurrey, V.K., Pandey, P.K., Bairwa, P.L., 2016. International Journal of Bio-resource and Stress Management 7(5), 964-969.

Srivastava, A., Gupta, A.K., Shankar, K., Gupta, M.M., Mishra, R., Lal, R.K., 2018. Genetic variability, associations, and path analysis of chemical and morphological traits in Indian ginseng [Withania somnifera (L.) Dunal] for selection of higher yielding genotypes 42(2), 158-164.

Ven Murthy, M.R., Ranjekar, P.K., Ramassamy, C., Deshpande, M., 2010. Scientific basis for the use of Indian ayurvedic medicinal plants in the treatment of neurodegenerative disorders: ashwagandha. Central Nervous System Agents in Medicinal Chemistry 10(3), 238-46. 